\title{
In vitro responses of human pulp cells and $3 T 3$ mouse fibroblasts to six contemporary dental restoratives
}

\author{
Jun Sun ${ }^{1}$, Yiming Weng ${ }^{2}$, Fengyu Song ${ }^{1}$, Dong $\mathrm{Xie}^{2}$ \\ ${ }^{1}$ Department of Oral Biology, School of Dentistry, Indiana University Indianapolis, Indianapolis, USA; \\ ${ }^{2}$ Department of Biomedical Engineering, Purdue School of Engineering and Technology, Indiana University-Purdue University at \\ Indianapolis, Indianapolis, USA. \\ Email: dxie@iupui.edu
}

Received 9 November 2010; revised 11 November 2010; accepted 12 November 2010.

\begin{abstract}
In vitro responses of human primary pulp cells (HPCs) and 3T3 mouse fibroblasts to six contemporary commercial dental restoratives were evaluated using the WST-1 assay. The results show that Fuji II is not cytotoxic to both cells. Fuji II LC is not cytotoxic to HPCs but cytotoxic to 3T3 cells, indicating that 3T3 cells are more vulnerable to 2-hydroxyethyl methacrylate (HEMA) than HPCs. Vitremer is very cytotoxic probably due to having diphenyliodonium chloride and HEMA in it. Z100 is very cytotoxic probably due to having triethylene glycol dimethacrylate (TEGDMA) in it. P60 is cytotoxic but less cytotoxic than Z100 probably due to no TEGDMA in it. Durelon is the most cytotoxic among the six materials studied probably due to the high cytotoxicity of zinc ions. Additionally, the cytotoxcity of the tested materials was found to be dose-dependent.
\end{abstract}

Keywords: In Vitro Cytotoxicity; Human Pulp Cells; 3T3 Mouse Fibroblast Cells; Dental Cement;

Glass-Ionomer Cement; Resin Composite

\section{INTRODUCTION}

It has been shown that components of dental restoratives can be released into the oral cavity [1-4] and cause adverse effects such as mucosal irritation, epithelial proliferation, oral lichenoid reaction, hypersensitivity and anaphylactoid reactions [5]. The released components from polymerized resin-based dental materials include residual or unreacted monomers, initiators, activators and other additives $[3,6,7]$. The resin-based dental materials include resin composites [8-10], dental bonding agents [11], resin-modified glass-ionomer cements (RMGICs) [3], conventional GICs (CGICs) [1-3], and other dental cements [12]. Among all these dental restoratives, CGICs are considered to be one of the most biocompati- ble restoratives $[3,12]$. On the other hand, RMGICs are less biocompatible due to release of unreacted monomers and other components [3]. Dental resin composites, a current substitute for dental amalgam, are applied in posterior cavity filling (stress-bearing sites), anterior teeth repair and core-building up restoration, due to their high-strength and high-wear-resistant nature [13-15]. Their biocompatibility is somehow still in question and debate due to release of unreacted monomers, oligomers and other low molecular weight components.

There are many ways to conduct a biocompatibility or cytotoxicity test $[12,13]$. In vitro cytotoxicity tests, a screening test, are efficient and relatively inexpensive to conduct although they are not as accurate as in vivo animal usage tests $[12,13]$. Cell culture studies are frequently used to assess the in vitro cytotoxicity of resin-based materials and their elutes or components such as monomers, oligomers and additives $[6,16]$. So far there have been numerous publications regarding in vitro cytotoxicity of various dental materials $[12,17]$. Some of them have been focused on evaluating the cytotoxicity of the pure monomers and oligomers $[12,17]$ and the other on testing the cytotoxicity of the eluates of the materials $[7,8,12,17,18]$. All the published results have made different contributions to the area of biocompatibility of dental restoratives $[5,12,17,18]$.

The objective of this study was to evaluate the in vitro cytotoxicity of six contemporary commercially available dental restoratives on human primary cells by testing the eluates using WST-1 assay. The 3T3 mouse fibroblast cell lines were evaluated for comparison. The effect of the eluate concentration on the cytotoxicity was studied as well.

\section{MATERIALS AND METHODS}

\subsection{Materials}

Fuji II (conventional glass-monomer cement) and Fuji II 
LC (light-cured glass-monomer cement) were used as received from GC America Inc (Alsip, IL). Durelon (zinc polycarboxylate cement), Vitremer (light-cured glass-monomer cement), Filtek Z100 (light-cured composite resin) and Filtek P60 (light-cured composite resin) were purchased from 3M ESPE (St. Paul, MN). The detailed information regarding the materials and their compositions are described in Table 1.

\subsection{Preparation of Specimens}

Cylindrical specimens of the materials used in this study were prepared at room temperature in glass tubing molds with dimensions of $4 \mathrm{~mm}$ in diameter by $2 \mathrm{~mm}$ in length [19]. A two-component (glass powder and liquid) system for Fuji II, Fuji II LC, Vitremer and Durelon and a single syringe (paste) system for Z100 and P60 were used and their specimens were prepared per manufacturers' instructions. For Fuji II and Durelon, specimens were prepared by thoroughly mixing glass powder and polymer liquid at a ratio of 2.7 and 2.0, respectively, followed by placing in the mold, conditioning in $100 \%$ humidity for $15 \mathrm{~min}$, removing from the mold and immediately sterilizing with 70\% alcohol. For Fuji II LC and Vitremer, specimens were prepared by thoroughly mixing glass powder and polymer liquid at a ratio of 3.2 and 2.5, respectively, followed by placing in the mold, exposing to blue light (EXAKT 520 Blue Light Polymerization Unit, $9 \mathrm{~W} / 71$, power $=30, \mathrm{WGmbH}$, Germany) for $2 \mathrm{~min}$, conditioning in $100 \%$ humidity for $15 \mathrm{~min}$, removing from the mold and immediately sterilizing with $70 \%$ alcohol. For Z100 and P60, specimens were prepared by placing the premixed paste from the product syringe into the mold, followed by exposing to blue light for $2 \mathrm{~min}$, conditioning in 100\% humidity for $15 \mathrm{~min}$, removing from the mold and immediately sterilizing with $70 \%$ alcohol.

\subsection{Preparation of Eluates of the Test Materials}

Immediately after removing form the molds, the specimens were quickly rinsed with $70 \%$ ethanol and sterile phosphate buffer saline (PBS), followed by immersing in a 48-well plate containing $300 \mu \mathrm{l}$ serum minus DMEM (Dulbecco's modified Eagle's medium or DMEM, Нyclone Laboratories, Inc. Logan, UT) in a humidified incubator at $37^{\circ} \mathrm{C}$ with $5 \% \mathrm{CO}_{2}$ and $95 \%$ air for 1,3 and 7 days, for preparation of eluates. The surface area to volume ratio was $1 \mathrm{~cm}^{2} / \mathrm{ml}$, which was set according to the ISO standards $\left(0.5-6.0 \mathrm{~cm}^{2} / \mathrm{ml}\right)$ [20]. Five specimens of each material for every eluate preparation were prepared and used for statistical analysis.

\subsection{Cell Culture Preparation}

Human pulp cells (HPCs) were isolated from the pulp tissue of healthy young permanent teeth undergoing orthodontic treatment, following the published protocol [21]. Briefly, the extracted teeth were cleaned consecutively with sterile PBS, 70\% ethanol and PBS, followed by cutting to obtain the pulp tissues. The tissues were then placed in a culture dish and minced to small pieces. Balb/c 3T3 mouse fibroblast cells were obtained directly from the American Type Culture Collection (Manassas, VA).

Either HPCs or $3 \mathrm{~T} 3$ cells were then cultured at $37^{\circ} \mathrm{C}$ in an air atmosphere containing 5\% $\mathrm{CO}_{2}$ and $95 \%$ relative humidity, with DMEM containing low glucose, supplemented with 10\% heat-inactivated fetal bovine serum (Hyclone Laboratories), $4 \mathrm{mM}$ L-glutamine (Hyclone Laboratories), $100 \mathrm{U} / \mathrm{ml}$ penicillin (Sigma-Aldrich, St. Louis, MO), $50 \mu \mathrm{g} / \mathrm{ml}$ gentamicin (Invitrogen Life Technologies, Carlsbad, CA) and $2.5 \mu \mathrm{g} / \mathrm{ml}$ amphotericin B fungizone (Lonza,Walkersville, MD). The HPCs which grew out of the pulp explants were sub-cultured

Table 1. Information related to the materials used in this study.

\begin{tabular}{|c|c|c|c|c|}
\hline Material & Type & Setting Mode & Liquid Composition $^{1}$ (by weight) & Glass Composition (by volume) \\
\hline Durelon & Polycarboxylate cement & Chemically cured & PAA, water & $\begin{array}{l}\text { Zinc oxide }(\text { most }) / \text { zinc } \\
\text { fluoride powder }\end{array}$ \\
\hline Fuji II & Conventional GIC & Chemically cured & PAAIA, water, tartaric acid & Ca-AI-F silicate glass powder \\
\hline Fuji II LC & Resin-modified GIC & Light-cured & TEGDMA, HEMA, PAA, water, CQ, DMAEMA & Sr-AI-F silicate glass powder \\
\hline Vitremer & Resin-modified GIC & Light-cured & $\begin{array}{l}\text { HEMA, PAA-g-IEM, water, tartaric acid, CQ, DC, } \\
\mathrm{K}_{2} \mathrm{~S}_{2} \mathrm{O}_{8} \text {, ascorbic acid }\end{array}$ & Al-F silicate glass powder \\
\hline P60 & Composite resin & Light-cured & BisGMA, UDMA, BisEMA, CQ, DMAEMA & $61 \% \mathrm{ZrO}_{2}-\mathrm{SiO}_{2}$ filler \\
\hline $\mathrm{Z} 100$ & Composite resin & Light-cured & BisGMA, TEGDMA, CQ, DMAEMA & $66 \% \mathrm{ZrO}_{2}-\mathrm{SiO}_{2}$ filler \\
\hline
\end{tabular}

${ }^{1}$ PAA $=$ poly(acrylic acid), PAAIA = poly(acrylic acid-co-itaconic acid), TEGDMA = triethylene glycol dimethacrylate, HEMA $=2$-hydroxyethyl methacrylate, $\mathrm{CQ}=$ camphorquinone, DMAEMA $=\mathrm{N}, \mathrm{N}$-dimethylaminoethyl methacrylate, PAA-g-IEM = poly(acrylic acid) grafted with 2-isocyanatoethyl methacrylate, DC = diphenyliodonium chloride, BisGMA = Bisphenol A glycidyl dimethacrylate, BisEMA = Bisphenol A polyethylene glycol diether dimethacrylate, and UDMA = urethane dimethacrylate. 
and maintained. The HPCs used for this study were taken between passage 3 and 8 .

\subsection{Evaluation of Cytotoxicity Using WST-1 Assay}

The water soluble tetrazolium salt-1 (WST-1) test was performed as described elsewhere [22,23]. Briefly, the cells were plated in a 96 -well plate at $2 \times 10^{3}$ cells per well in $100 \mu \mathrm{l}$ of DMEM supplemented with $10 \%$ FBS, $100 \mathrm{U} / \mathrm{ml}$ penicillin and $100 \mu \mathrm{g} / \mathrm{ml}$ streptomycin. After incubation at $37^{\circ} \mathrm{C}$ overnight, the medium was replaced with $100 \mu \mathrm{l}$ of the fresh medium containing different concentrations of eluate $(0 \%, 10 \%, 20 \%, 40 \%, 60 \%$ and $80 \%$ ). The cells were then incubated for $72 \mathrm{~h}$ before the WST testing. The positive control was serum minus DMEM with untreated cells and the negative control was serum minus DMEM without cells. The WST-1 test was conducted by adding $10 \mu \mathrm{l}$ of WST-1 reagent (Roche Diagnostics, Indianapolis, IN) and $90 \mu \mathrm{l}$ of serum minus DMEM into a well and then incubating the plate at $37^{\circ} \mathrm{C}$ for $2 \mathrm{~h}$. The absorbance of the solution was measured at $450 \mathrm{~nm}$ using a microplate reader (Molecular devices, Sunnyvale, CA). Cell viability (\%) was obtained by the equation: cell viability $(\%)=($ absorbance of the sample elaute-absorbance of the negative control)/(absorbance of the positive control-absorbance of the negative control) $\times 100 \%$. Cell morphology was obtained at $100 \mathrm{X}$ magnification using Nikon eclipse TS100 microscope (Nikon Corp., Japan).

\subsection{Statistical Analysis}

One-way analysis of variance (ANOVA) with the post hoc Tukey-Kramer multiple range test was used to determine significant differences of in vitro cytotoxicity among the materials. A level of $\alpha=0.05$ was used for statistical significance.

\section{RESULTS}

Figure 1(a) shows the HPC viability after the cells were cultured with the eluates of the six materials tested at a concentration of $80 \%$. Fuji II and Fuji II LC showed the highest cell viability, respectively, after cell exposure to 1-day and 3-day eluates. Durelon showed the lowest viability. The viability (\%) was in the decreasing order: (1) for the 1-day eluate, Fuji II $(100.3 \pm 6.3)>$ Fuji LC $(88.0 \pm 11)>\mathrm{P} 60(54.2 \pm 7.2)>\operatorname{Vitremer}(37.9 \pm 3.8)>$ Z100 $(12.4 \pm 2.7)>$ Durelon $(0.19 \pm 0.3)$, where Z100 and Durelon, Fuji LC and Fuji II, and Vitremer and P60 were not significantly different from each other $(\mathrm{p}>$ 0.05); (2) for the 3-day eluate, Fuji LC (105.9 \pm 10.3$)>$ Fuji II $(98.8 \pm 7.8)>$ P60 $(50.7 \pm 3.6)>$ Vitremer $(27.1 \pm$ $5.3)>\mathrm{Z} 100(6.82 \pm 3.7)>$ Durelon $(0.39 \pm 0.9)$, where Z100 and Durelon as well as Fuji LC and Fuji II were not significantly different from each other $(\mathrm{p}>0.05)$.

Figure 1(b) shows the $3 \mathrm{~T} 3$ fibroblast viability after the cells were cultured with the eluates of the six materials tested at a concentration of $80 \%$. Fuji II showed the highest cell viability but Z100 showed the lowest viability. The viability (\%) was in the decreasing order: 1$)$ for the 1-day eluate, Fuji II $(99.4 \pm 2.3)>$ P60 $(64.9 \pm 8.4)>$ Fuji LC $(53.6 \pm 2.9)>$ Durelon $(2.63 \pm 2.6)>$ Vitremer $(0.78 \pm 0.7)>Z 100(0.47 \pm 1.9)$, where Vitremer, Z100 and Durelon were not significantly different from one another $(\mathrm{p}>0.05) ; 2)$ for the 3-day eluate (Figure 2(b)), Fuji II $(100.8 \pm 5.5)>$ P60 $(70.4 \pm 6.1)>$ Fuji LC $(68.0 \pm$ $3.3)>$ Vitremer $(4.89 \pm 0.3)>$ Durelon $(3.15 \pm 0.4)>$ Z100 (0.07 \pm 2.3$)$, where Vitremer, Z100 and Durelon as well as Fuji LC and P60 were not significantly different from each other $(\mathrm{p}>0.05)$.

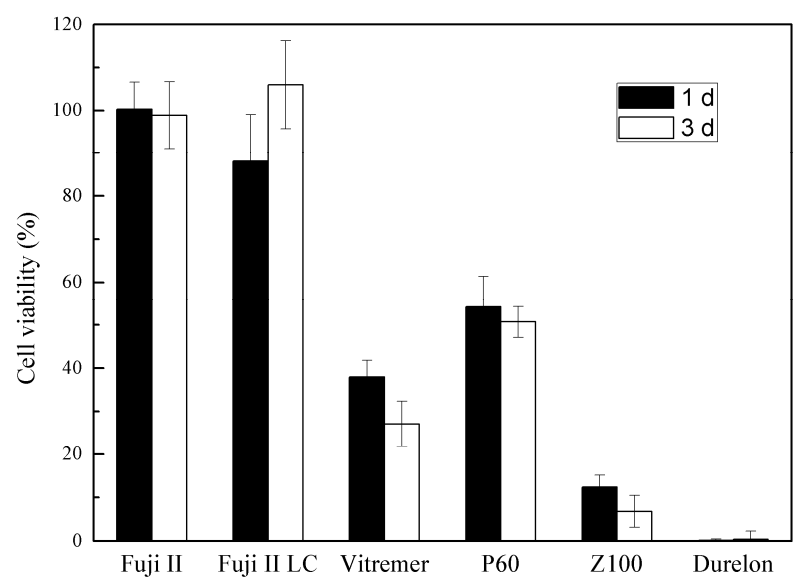

(a)

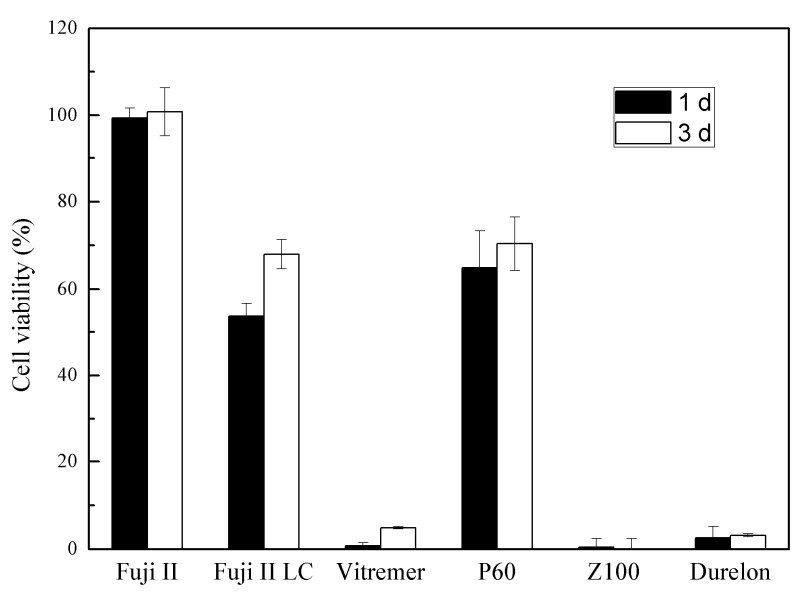

(b)

Figure 1. Cell viability comparison after cultured with the eluates from different cements for $72 \mathrm{~h}$; (a) HPC viability comparison; (b) 3T3 fibroblast viability comparison. Eluates were obtained from the 1-day and 3-day incubation at a concentration of $80 \%$. 
Figures 2(a) and (b) show the HPC viability vs. eluate concentration at the 1-day and 3-day extractions, respectively. For the 1-day eluate, Fuji II showed no cytotoxicity at all; Fuji II LC showed nearly no cytotoxicty; Vitremer, P60, Z100 and Durelon started to show the cytotoxicty, respectively, at a concentration of $20,80,40$ and $40 \%$, with the viability values of 80,54 , 66 and 4.8\%. For the 3-day eluate, both Fuji II and Fuji II LC showed no cytotoxicity; Vitremer, P60, Z100 and Durelon started to show the cytotoxicty, respectively, at a concentration of $20,40,10$ and $40 \%$, with the viability values of $70,68,85$ and $0.5 \%$.

Figures 3(a) and (b) show the 3T3 fibroblast viability vs. eluate concentration at the 1-day and 3-day extractions, respectively. For the 1 day eluate, Fuji II showed

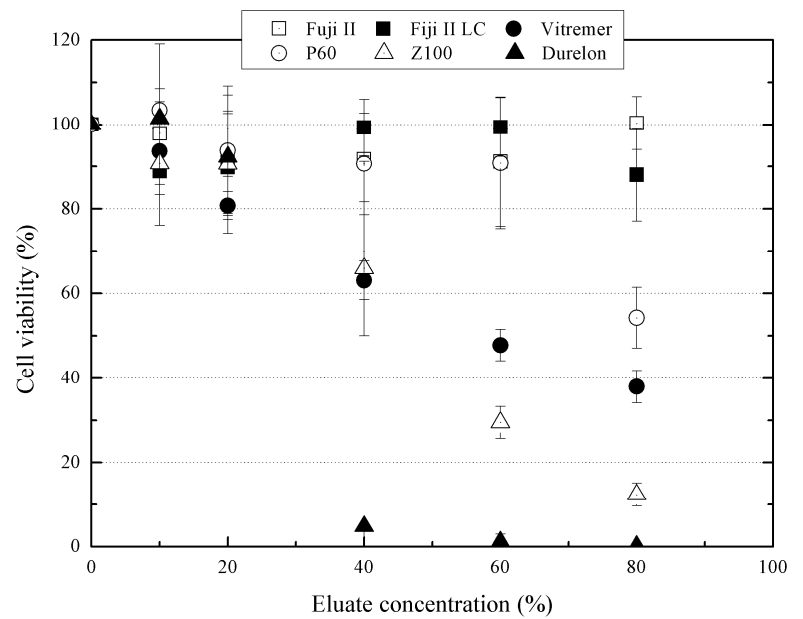

(a)

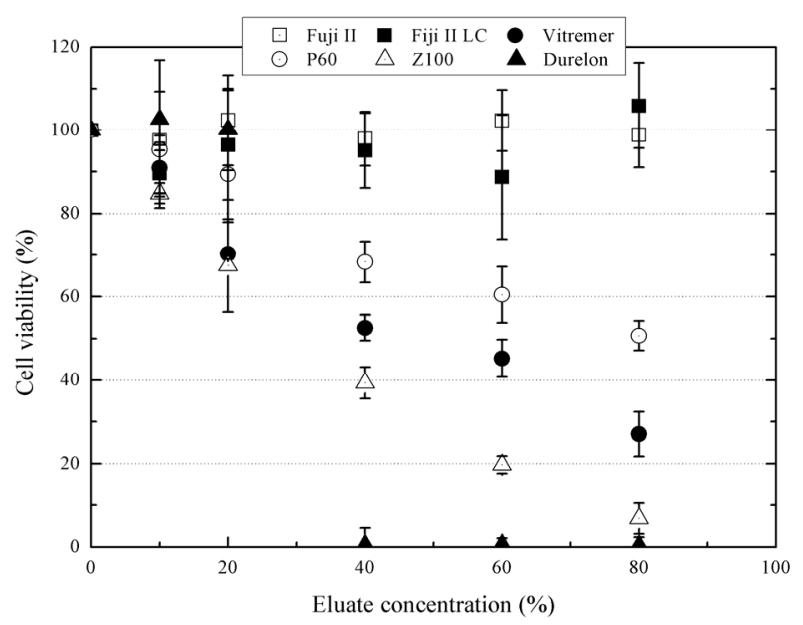

(b)

Figure 2. HPC viability (\%) vs. cement eluate concentration: (a) eluates obtained from the 1-day incubation; (b) eluates obtained from the 3-day incubation. The cells were incubated with the medium containing different concentrations of the eluates at $37^{\circ} \mathrm{C}$ for $72 \mathrm{~h}$ before WST-1 testing.

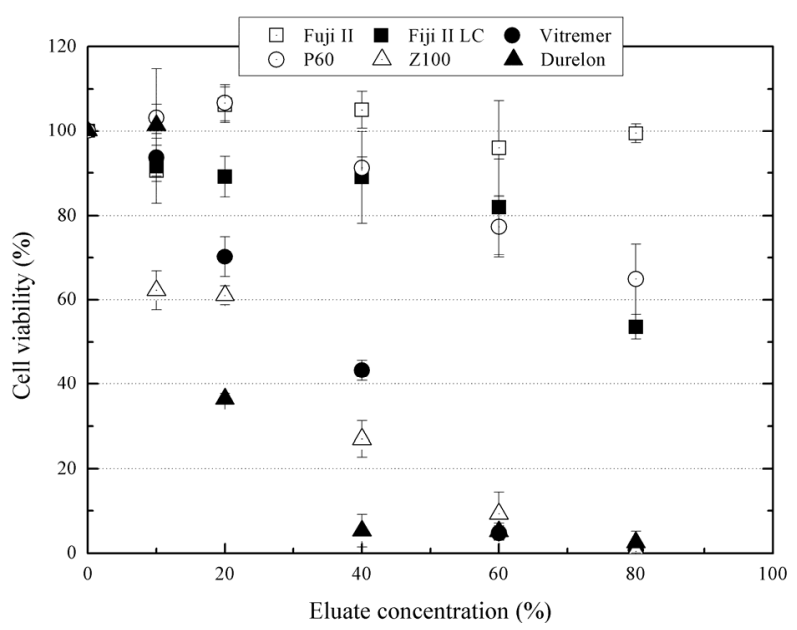

(a)

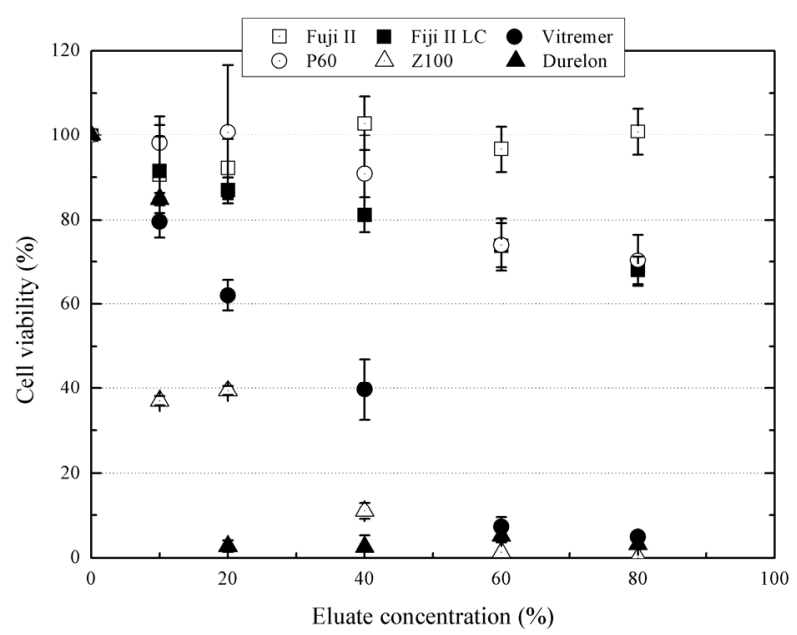

(b)

Figure 3. 3T3 fibroblast viability (\%) vs. cement eluate concentration: (a) eluates obtained from the 1-day incubation; (b) eluates obtained from the 3-day incubation. The cells were incubated with the medium containing different concentrations of the eluates at $37^{\circ} \mathrm{C}$ for $72 \mathrm{~h}$ before WST-1 testing.

no cytotoxicity; Fuji II LC, Vitremer, P60, Z100 and Durelon started to show the cytotoxicty, respectively, at a concentration of $60,20,60,10$ and $20 \%$, with the viability values of $82,70,77,62$ and $36 \%$. For the 3 -day eluate, Fuji II showed no cytotoxicity at all. Fuji II LC, Vitremer, P60, Z100 and Durelon started to show the cytotoxicty, respectively, at a concentration of $20,10,60$, 10 and $10 \%$, with the viability values of $87,79,74,37$ and $85 \%$.

Figure 4 is a set of optical photomicrographs describing the HPC morphology after contact with the corresponding 3-day eluate. Figures 4(a-g) represent the HPC morphology after cultured with blank, Fuji II, Fuji II LC, Vitremer, P60, Z100 and Durelon, respectively. In Figures 4(a) (control) and (b) (Fuji II), numerous healthy 


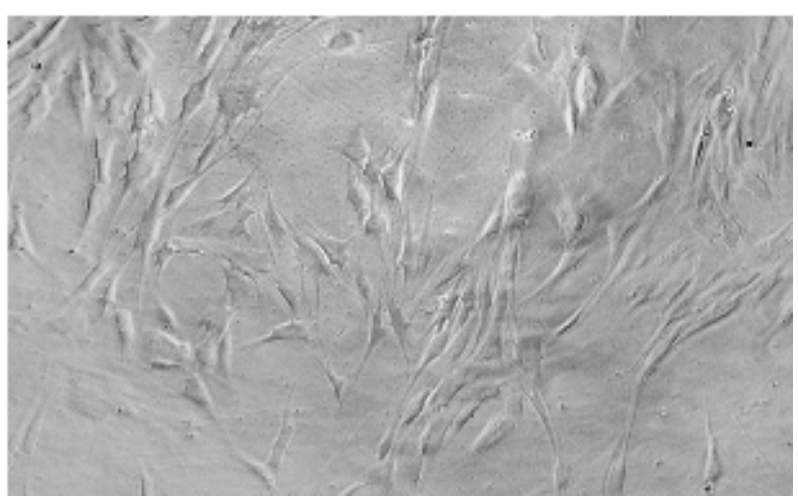

(a)

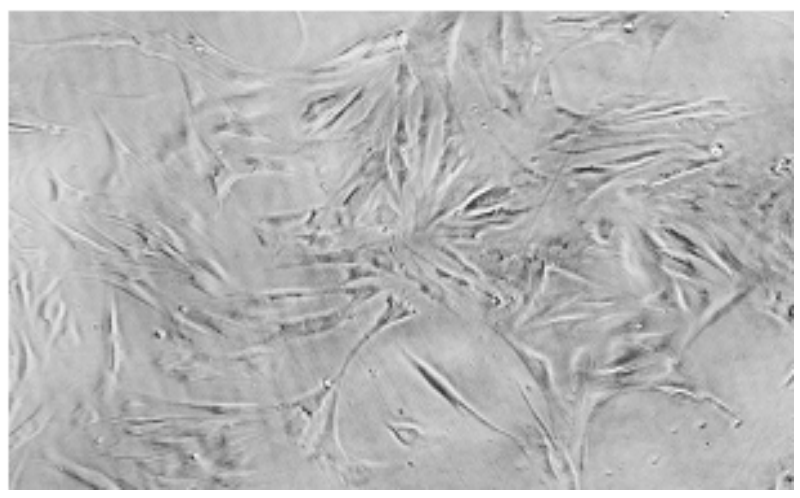

(b)

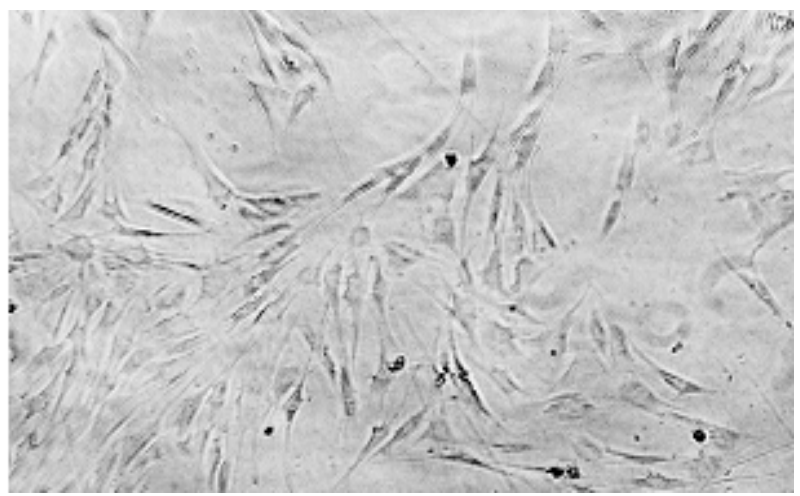

(c)

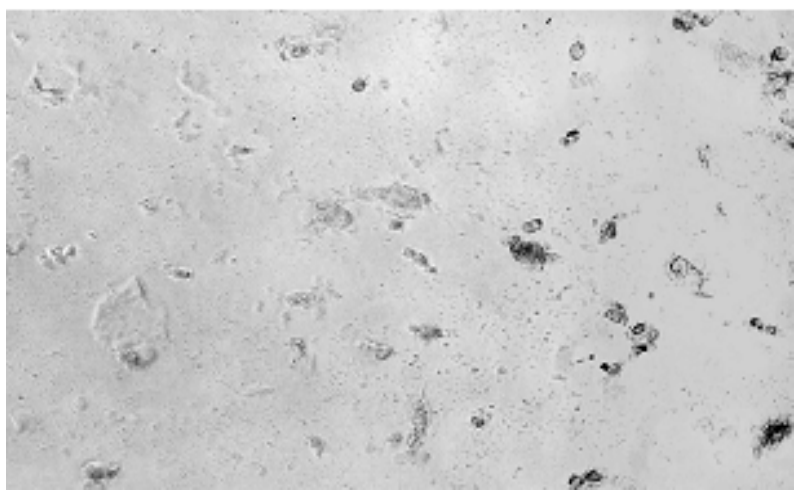

(d)

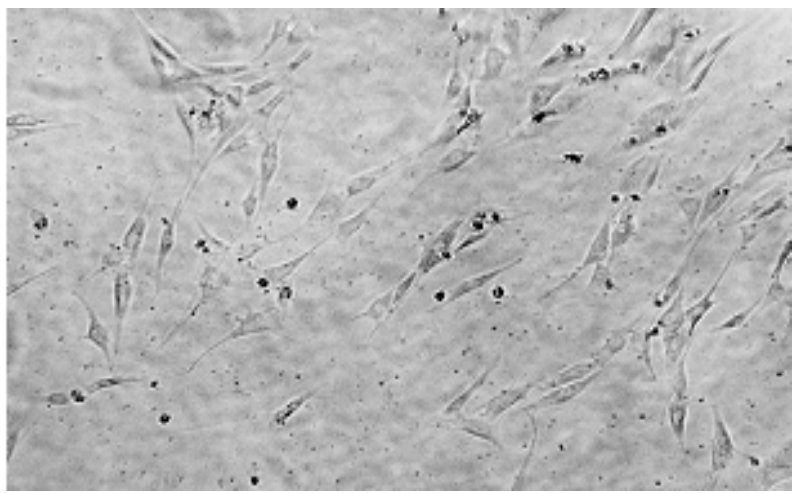

(e)

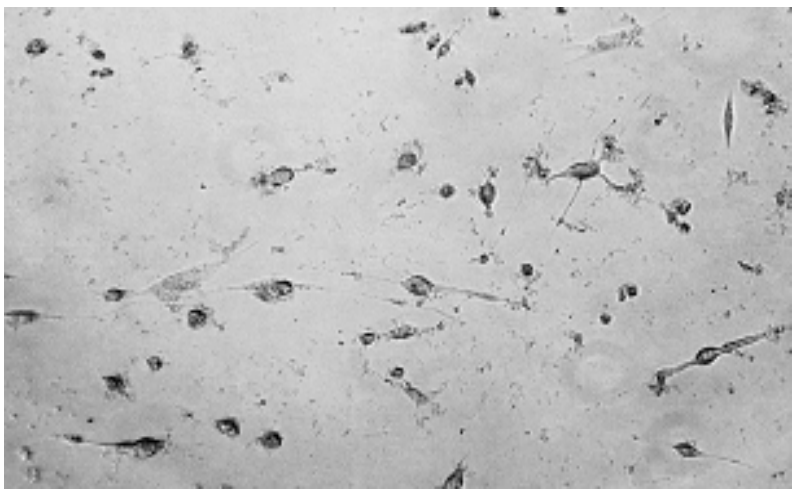

(f)

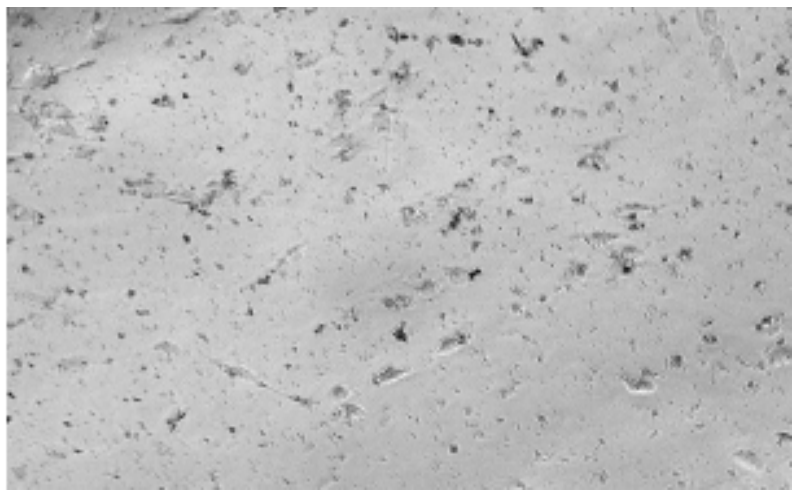

(g)

Figure 4. HPC morphology and density (100X magnification): (a) HPC; (b) Fuji II; (c) Fuji II LC; (d) Vitremer; (e) P60; (f) Z100; (g) Durelon. Cell morphology photomicrograph was obtained after the cells incubated with the 3-day eluates for $72 \mathrm{~h}$.

cells with an elongated and spindle shape (typical HPC morphology) are observed. In Figure 4(c) (Fuji II LC) and e (P60), some small black round spots (dead or unhealthy cells) are observed although there still exist many elongated and spindle shaped cells. In Figures 4(d) (Vitremer), (f) (Z100) and (g) (Durelon), large black spots (condensed irregular nuclei of the dead cells) are clearly seen and the intact cells disappeared. Furthermore, the 
lysed cell pieces are found in Figure 4(g)

Figure 5 is a set of optical photomicrographs describing the $3 \mathrm{~T} 3$ cell morphology after contact with the corresponding 3-day eluate. In Figures 5(a) (control) and (b) (Fuji II), numerous cells with a multipolar shape (typical 3T3 cell morphology) are observed. In Figure 5(c) (Fuji II LC) and e (P60), black spots (dead cells) and deformed 3T3 cells are clearly seen, although the multipolar-shaped cells are still noticed. In Figure 5(d) (Vitremer) and $\mathrm{f}$ (Z100), nearly no multipolar-shaped cells are observed except for the round dead cells. In Figure 5(g), the cells are found to be significantly lysed and different sizes of black spots or lysed pieces are noticed everywhere.

\section{DISCUSSION}

Biocompatibility of dental restoratives is very important in dentistry [1-3]. Non-biocompatible or cytotoxic materials can cause short-term or long-term tissue inflammation or cell death [1-5]. Regarding dental cavity filling restoratives, the most critical concern for biocompatibility is the cytotoxcity caused by the leachable components such as unreactive monomers, initiators and other additives form the organic resins or cytotoxic metal ions from the inorganic fillers. These leachable components can penetrate into pulp chamber through dental tubules and cause pulp inflammation [1,5]. In this study, we evaluated six contemporary commercial dental filling restoratives including Fuji II, Fuji II LC, Vitremer, P60, Z100 and Durelon. Their compositions are shown in Table 1 [24-30]. It is known that chemistry and potentially leachable components ultimately determine the cytotoxicity of the filled restoratives [1-4].

\subsection{Chemistry Involved in the Setting Reactions of the Tested Materials and Potential Leachable Species}

\subsubsection{Durelon}

Durelon is a chemically-cured dental luting cement. It is composed of zinc oxide, zinc fluoride, polycarboxylic acid and water. An acid-base reaction between zinc cations released from a $\mathrm{ZnO} / \mathrm{ZnF}_{2}$ glass and carboxyl anions pendent on polycarboxylic acid describes the setting reaction mechanism in Durelon [13,31]. During the setting reaction, with the help of water the surface of the $\mathrm{ZnO} / \mathrm{ZnF}_{2}$ glass particles reacts with the carboxyl groups pendent from polycarboxylate to form zinc carboxylate salt-bridges and hardens the cement. It is known that not all the glass particles participate in the setting reaction [13]. Therefore, the unreacted zinc cations can leach out of the cement. The polycarboxylic acid is hardly leachable due to its high molecular weight (MW) $[3,13]$.

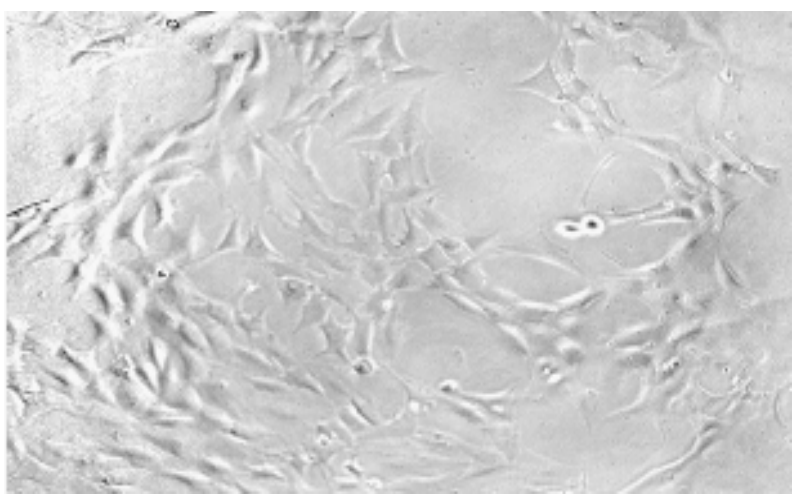

(a)

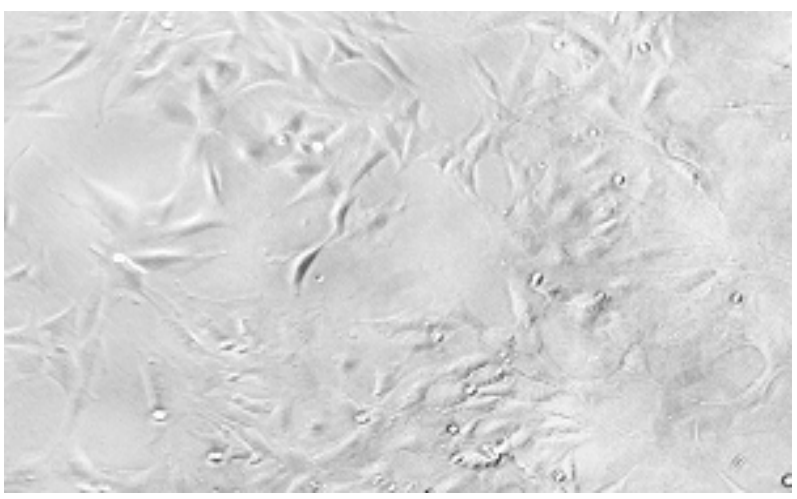

(b)

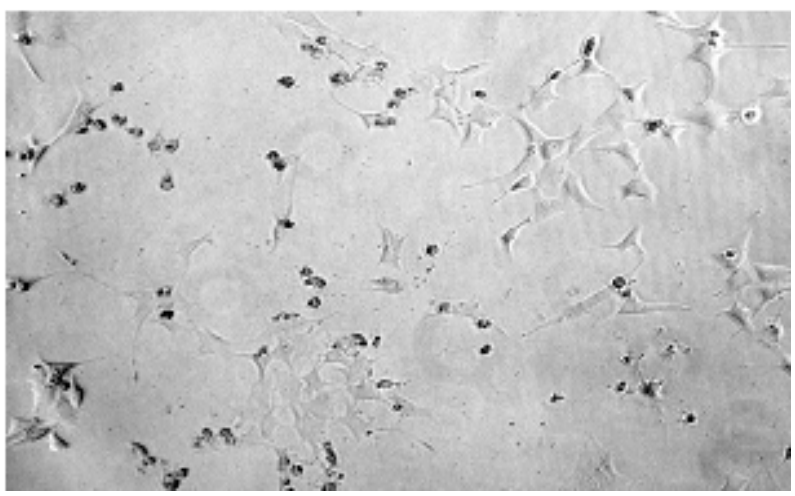

(c)

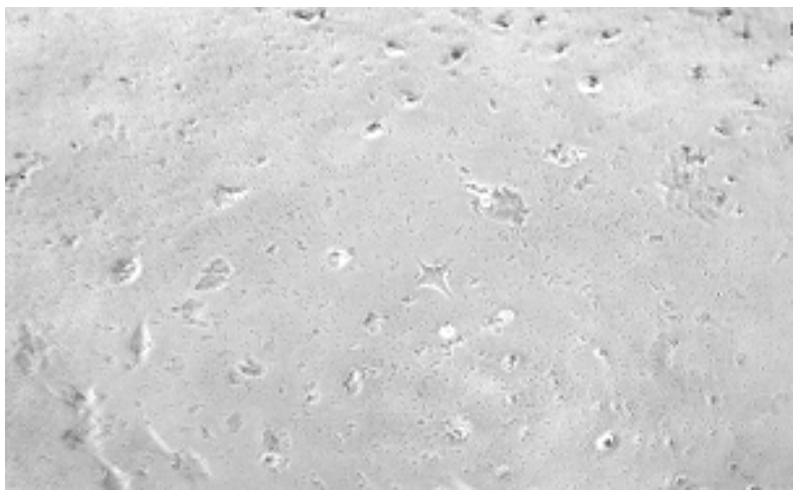

(d) 


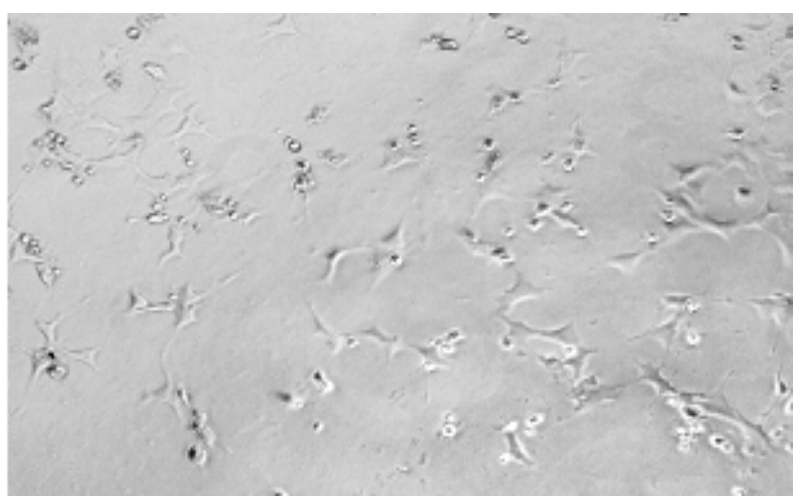

(e)

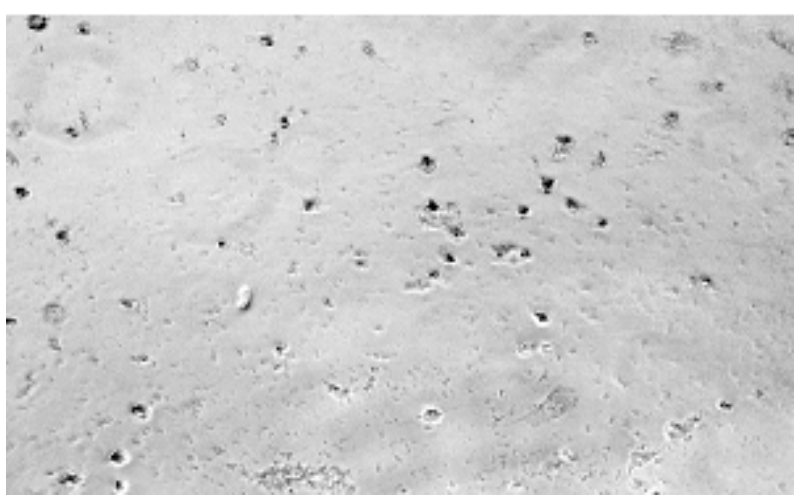

(f)

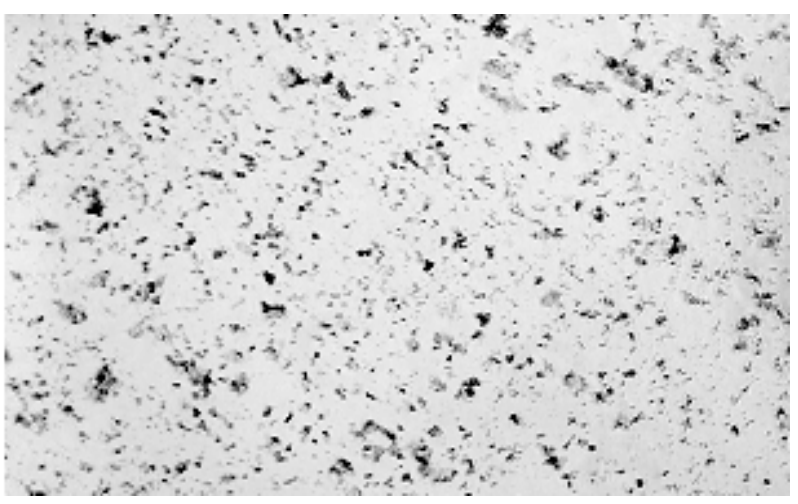

(g)

Figure 5. 3T3 fibroblast morphology and density (100X magnification): (a) HPC; (b) Fuji II; (c) Fuji II LC; (d) Vitremer; (e) P60; (f) Z100; (g) Durelon. Cell morphology photomicrograph was obtained after the cells incubated with the 3-day eluates for $72 \mathrm{~h}$.

\subsubsection{Fuji II}

Fuji II is a chemically-cured glass-ionomer cement (GIC) used for dental luting and filling purposes. It is composed of calcium aluminofluorosilicate glass powder, polycarboxylic acid (a copolymer of acrylic acid and itaconic acid), tartaric acid (TA) and water, where TA is used for extending the working time. An acid-base reac- tion between calcium as well as aluminum cations released from a reactive sintered glass and carboxyl anions pendent on polyacid describes the setting mechanism in conventional GIC [32]. During the setting reaction, with the help of water the surface of the sintered glass particles reacts with the carboxyl groups pendent on polycarboxylate to form three-dimensional aluminum-carboxylate/calcium-carboxylate salt-bridges and hardens the cement. The polymer is hardly leachable. Although not all the glass particles participate in the setting reaction, the unreacted glass particles do not easily leach out of the cement because they are sintered $[32,33]$.

\subsubsection{Fuji II LC}

Fuji II LC is a light-cured resin-modified GIC (RMGIC) mainly used for cavity filling and core-building purposes. It is composed of strontium aluminofluorosilicate glass powder, 2-hydroxylethyl methacrylate (HEMA), triethylene glycol dimethacrylate (TEGDMA), poly(acrylic acid), water, camphorquinone (CQ) and dimethylaminoethyl methacrylate (DMAEMA), where CQ and DMAEMA are used for initiating the photo polymerization. Except for the acid-base reaction similar to that in Fuji II, HEMA and TEGDMA can copolymerize to form a crosslinked network via covalent bond formation upon blue light initiation. This polymer network is somehow stronger than that formed by salt-bridges in Fuji II, especially in toughness and tensile strength $[13,29]$. However, unreacted HEMA as well as TEGDMA due to the limited conversion in situ [12] and CQ as well as DMAEMA may possibly leach out of the cement. The sintered glass particles, like the glass in Fuji II, usually do not easily leach out from Fuji II LC [33].

\subsubsection{Vitremer}

Vitremer is a tri-cured RMGIC mainly used for dental luting. It contains aluminofluorosilicate glass powder, HEMA, poly(carboxylic acid) with pendent methacrylate groups, TA, water, potassium persulfate $\left(\mathrm{K}_{2} \mathrm{~S}_{2} \mathrm{O}_{8}\right)$, ascorbic acid, $\mathrm{CQ}$ and diphenyliodonium chloride (DC), where TA, $\mathrm{K}_{2} \mathrm{~S}_{2} \mathrm{O}_{8}$, ascorbic acid, $\mathrm{CQ}$ and DC are used for adjusting the working time and initiating the redox as well as photo polymerizations. Except for the acid-base and photo polymerization reactions shown in Fuji II LC, there also exists a redox polymerization initiated by a pair of redox initiators $\mathrm{K}_{2} \mathrm{~S}_{2} \mathrm{O}_{8}$ and ascorbic acid. The photo-activator used in Vitremer is also different from that used in Fuji II LC, i.e., Vitremer uses DC but Fuji II LC uses DMAEMA instead [6,29]. Furthermore, Vitremer uses HEMA and polycarboxylic acid with pendent methacrylate groups to form a crosslinked polymer network via both photo- and redox-initiated polymerizations [6,29]. Like those in Fuji II and Fuji II LC, the sintered glass particles usually do not leach out [33]. The 
potential leachable components in Vitremer include unreacted HEMA, CQ, DC, TA, $\mathrm{K}_{2} \mathrm{~S}_{2} \mathrm{O}_{8}$ and ascorbic acid.

\subsubsection{Z100 and P60}

$\mathrm{Z} 100$ is a light-cured resin composite for cavity filling. It contains $\mathrm{ZrO}_{2}-\mathrm{SiO}_{2}$ fillers, bisphenol A diglycidyl ether dimethacrylate (BisGMA), TEGDMA, CQ and DMAEMA, where CQ and DMAEMA are used for initiating the photo polymerization. P60 is also a light-cured resin composite but it is an improved version of Z100. In P60, except for $\mathrm{ZrO}_{2}-\mathrm{SiO}_{2}$ fillers, BisGMA, CQ and DMAEMA, TEGDMA is replaced by a mixture of urethane dimethacrylate (UDMA) and bisphenol A polyethylene glycol diether dimethacrylate (BisEMA). It is claimed to have lower shrinkage as well as reduced aging and be more hydrophobic as well as less sensitive to changes in atmospheric moisture. Upon the photo initiation the dimethacrylate oligomers in the formulations lead to formation of the crosslinked polymer networks. Unlike those in either GICs or zinc polycarboxylate cement, the glass particles in resin composites are only used as fillers and do not participate in any chemical reactions. They are usually inert to cells or tissues $[12,13]$. The difference between Z100 and P60 lies in that the former contains TEGDMA but the latter contains UDMA and BisEMA. Due to higher MWs of UDMA and BisEMA, the resin liquid in the $\mathrm{P} 60$ formulation is more viscous. P60 is also claimed to have lower shrinkage as well as reduced aging and be more hydrophobic as well as less sensitive to changes in atmospheric moisture. The potential leachable components in Z100 are TEGDMA, CQ and DMAEMA whereas those in P60 are UDMA, BisEMA, CQ and DMAEMA. The unreacted BisGMA (if any) is hardly leachable due to its higher hydrophobicity and MW.

\subsection{In Vitro Cytotoxicty}

Two types of cells, HPC and 3T3 fibroblast, were used to evaluate the cytotoxicity of the six materials. HPCs were isolated directly from pulp tissues of human teeth whereas 3T3 mouse fibroblasts were cultured cell lines. As compared to $3 \mathrm{~T} 3$ cells, HPCs are more clinically relevant. In this study the WST-1 assay was used as a tool to evaluate the cytotoxicity. The WST-1 is a colorimetric assay based on the cleavage of the water soluble tetrazolium salt (WST-1) by mitochondrial dehydrogenases to a yellow-orange formazan and is claimed to be a more sensitive assay than MTT [23].

From Figures 1(a) and (b), Fuji II was the most biocompatible but Durelon was the most cytotoxic. The results are interpreted below with the help of the compositions discussed in the previous section. For Fuji II, this cement simply consists of a sintered calcium aluminofluorosilicate glass powder, polycarboxylic acid, TA and water. During the initial setting, the $\mathrm{Al}^{3+}$ and $\mathrm{Ca}^{2+}$ react with $-\mathrm{COO}^{-}$groups. Although there may be a very small amount of $\mathrm{Al}^{3+}$ and $\mathrm{Ca}^{2+}$ ions leached, it would not cause any significant cytotoxicity [33]. Meanwhile, there may be some leachable polycarboxylic acid and TA [34]; However, these acidic species would not cause any significant cytotoxicity as well because the tested specimens were immersed in DMEM where these acidic species could be buffered. That is why Fuji II showed no cytotoxicity at all to both cells. For Fuji II LC, this cement showed nearly no cytotoxicity to HPCs but was cytotoxic to 3T3 cells. Except for the similar components shown in Fuji II, Fuji II LC also contains HEMA (30-60\% by weight), TEGDMA (1-5\%), CQ and DMAEMA. Among them, CQ and DMAEMA are considered to be the least toxic [7] and only $1-2 \%$ of them are included in the formulation $[13,29]$. It was found that both HEMA and TEGDMA were cytotoxic and TEGDMA was even more cytotoxic than HEMA $[6,7]$. However, there was only a very small amount of TEGDMA in Fuji II LC and most of it was crosslinked with HEMA. That may be why Fuji II LC showed a better biocompatibility than the other tested materials except for Fuji II. Furthermore, by comparing the cell viability results between HPCs and 3T3 cells, we found that 3T3 cells were more sensitive to HEMA and TEGDMA (if any) than HPCs. In other words, 3T3 cells responded more sensitively than HPCs. For Vitremer, we found that this cement was the most cytotoxic restorative among the three GICs tested. Except for the components shown in Fuji II and HEMA as well as CQ shown in Fuji II LC, Vitremer also contains polycarboxylic acid with pendent methacrylate groups, $\mathrm{K}_{2} \mathrm{~S}_{2} \mathrm{O}_{8}$, ascorbic acid and DC. DC was found to be the most cytotoxic component to be responsible for the cell death in Vitremer and Vitrobond [29]. Both DC and HEMA are the main possible reason to cause very low cell viability values $[6,7,29]$. In addition, similar to the results for Fuji II LC, HPCs showed higher viability values than $3 \mathrm{~T} 3$ cells, indicating that 3T3 cells are more vulnerable to both DC and HEMA. For $\mathrm{Z100}$, this resin composite contains $\mathrm{ZrO}_{2}-\mathrm{SiO}_{2}$ fillers, BisGMA (approximately $50 \%$ by mole), TEGDMA (approximately 50\%), CQ and DMAEMA. Except for CQ and DMAEMA, both BisGMA and TEGDMA were found to be very cytotoxic and BisGMA was even more cytotoxic than TEGDMA when testing in a DMSO/water mixture [7]. However, since BisGMA is more hydrophobic than TEGDMA $[7,12]$ and its MW $(\mathrm{MW}=512)$ is also higher than that of TEGDMA ( $\mathrm{MW}=286)$, the leaching probability of BisGMA in aqueous solution is much lower than that for TEGDMA. A substantial amount of TEGDMA in Z100 should be responsible for its high cytotoxicity. Furthermore, HPCs seemed less 
vulnerable to Z100 than $3 \mathrm{~T} 3$ cells. The similar result was also demonstrated elsewhere [18]. For P60, this resin composite was not as cytotoxic as Z100. Except for the same fillers, BisGMA, CQ and DMAEMA present in Z100, P60 does not contain TEGDMA but contains UDMA and BisEMA instead [27]. Because both UDMA $(\mathrm{MW}=470)$ and BisEMA $(\mathrm{MW}=540)$ have higher MWs and are more hydrophobic than TEGDMA (MW = 286), their mobility and aqueous solubility, respectively, should be slower and lower than TEGDMA. Although BisGMA, UDMA and BisEMA were found to be more cytotoxic in the DMSO/water mixture than TEGDMA $[7,12]$, TEGDMA is more leachable in aqueous solution or culture medium than both due to its lower MW and higher hydrophilicity. That is why P60 showed considerably lower cytotoxicity than Z100. For Durelon, this is a dental luting cement and its setting chemistry is very similar to most conventional GICs such as Fuji II. Except for polycarboxylic acid and water, Durelon uses zinc oxide and zinc fluoride as a reactive glass in its system. Zinc cations are found to be very cytotoxic in vitro and considered to be a dangerous cations to cells, unless combining with other cations such as $\mathrm{Fe}^{++}$or $\mathrm{Ca}^{++}$ [35]. As mentioned earlier, polycarboxylic acid would not lead to cytotoxcity due to buffering of the culture medium. However, leachable zinc cations especially from zinc fluoride can cause significant cytotoxicity to surrounding cells or tissues. Apparently the zinc-containing cement Durelon showed the highest cytotoxcity to both cells.

The results from Figures 2 and 3 clearly indicate that the cytotoxicity of the tested materials was dose-dependent, as reported elsewhere [36]. In the case of HPCs (Figure 2), Fuji II showed no cytotoxicity at all the eluate concentrations to both 1-day and 3-day extractions. Fuji II LC showed nearly no cytotoxicity at all the eluate concentrations. Vitremer started to show the cytotoxicity with the cell viability of $80 \%$ and $70 \%$ at $20 \%$ and ended up with $38 \%$ and $27 \%$ at $80 \%$ for the 1-day and 3-day eluates, respectively, suggesting that at a concentration of $20 \%$ the components in Vitremer started to kill the cells. P60 started to show the cytotoxcity with the cell viability of $54 \%$ at $80 \%$ for the 1 -day eluate and $68 \%$ at $40 \%$ and $51 \%$ at $80 \%$ for the 3-day eluate, suggesting that the components in P60 release very slowly. Z100 started to show the cytotoxicity with the viability of $66 \%$ at $40 \%$ and $85 \%$ at $10 \%$ and ended up with $12 \%$ and $6.8 \%$ at $80 \%$, suggesting that a large quantity of TEGDMA in Z100 lead to higher cytotoxicity. Durelon started to show the cytotoxicity with the viability of $4.8 \%$ and $0.5 \%$ at $40 \%$ and ended up with $0.2 \%$ and $0.4 \%$ at $80 \%$. The results indicate that HPCs can tolerate the eluate concentration below $40 \%$ in Durelon. However, once reaching $40 \%$, the cells almost completely died, suggesting that above a certain concentration threadshold the zinc ions are deadly species to cells, unless it can be buffered or combined with other cations such as $\mathrm{Fe}^{++}$or $\mathrm{Ca}^{++}$[35].

Considering 3T3 cells (Figure 3), only Fuji II showed no cytotoxicity at all the eluate concentrations. Fuji II LC started to show the cytotoxicity with the cell viability of $82 \%$ at $60 \%$ and $86 \%$ at $20 \%$ and ended up with $54 \%$ and $68 \%$ at $80 \%$, for the 1 -day and 3 -day eluates, respectively. The results suggest that Fuji II LC is selectively cytotoxic to $3 \mathrm{~T} 3$ cell lines but not to human primary cells. The results were consistent with those published elsewhere $[18,19]$. Vitremer started to show the cytotoxicity with the cell viability of $70 \%$ at $20 \%$ and $80 \%$ at $10 \%$ and ended up with $4.9 \%$ and $0.8 \%$ at $80 \%$. By comparing with HPCs, 3T3 is more vulnerable to Vitremer. P60 started to show the cytotoxicity with the cell viability of $77 \%$ and $74 \%$ at $60 \%$ and ended up with $65 \%$ and $70 \%$ at $80 \%$. Z100 started to show the cytotoxicity with the viability of $62 \%$ and $37 \%$ at $10 \%$ and ended up with $0.5 \%$ and $0.1 \%$ at $80 \%$. Durelon started to show the cytotoxicity with the viability of $36 \%$ at $20 \%$ and $80 \%$ at $10 \%$ and ended up with $2.6 \%$ and $3.2 \%$ at $80 \%$, indicating that $3 \mathrm{~T} 3$ cells can tolerate the eluate concentration of Durelon below 10 or $20 \%$. Comparing with HPCs, 3T3 showed lower tolerance to Durelon.

From the photomicrographs shown in Figures 4 and 5, it is clear that the results for cell morphology matched those shown for the cell viability and well explained the cell viability values described in Figure 1.

\section{CONCLUSIONS}

In vitro responses of human primary pulp cells (HPCs) and 3T3 mouse fibroblasts to six contemporary dental restoratives on HPCs and 3T3 mouse fibroblasts were tested. Fuji II is not cytotoxic to both cells. Fuji II LC is not cytotoxic to HPCs but cytotoxic to $3 \mathrm{~T} 3$ cells. Vitremer is very cytotoxic probably due to having DC and HEMA in it. Z100 is very cytotoxic probably due to having a large quantity of TEGDMA in it. P60 is cytotoxic but less cytotoxic than Z100 probably due to no TEGDMA in it. Durelon is the most cytotoxic among the tested materials probably due to the high cytotoxicity of zinc ions. It was found that 3T3 cell lines were more vulnerable to leachable cytotoxic components than primary HPCs. It was also found that the cytotoxcity of the tested materials was dose-dependent.

\section{ACKNOWLEDGEMENTS}

This work was partially sponsored by NIH challenge grant (RC1) 
DE020614.

\section{REFERENCES}

[1] Modena, K.C., Casas-Apayco, L.C., Atta, M.T., Costa, C.A., Hebling, J., Sipert, C.R., Navarro, M.F. and Santos, C.F. (2009) Cytotoxicity and biocompatibility of direct and indirect pulp capping materials. Journal of Applied Oral Science, 17, 544-54. doi:10.1590/S1678-77572009000600002

[2] Polyzois, G.L. (1994) In vitro evaluation of dental materials. Clinical Materials, 16, 21-60. doi:10.1016/0267-6605(94)90088-4

[3] Nicholson, J.W. and Czarnecka, B. (2008) The biocompatibility of resin-modified glass-ionomer cements for dentistry. Dental Materials, 24, 1702-1708.

doi:10.1016/j.dental.2008.04.005

[4] Spahl, W., Budzikiewicz, H. and Geurtsen, W. (1998) Determination of leachable components from four commercial dental composites by gas and liquid chromatography/mass spectrometry. Journal of Dentistry, 26, 137145. doi:10.1016/S0300-5712(96)00086-3

[5] Hensten-Pettersen, A. (1998) Skin and mucosal reactions associated with dental materials. European Journal of Oral Sciences, 106, 707-712.

[6] Geurtsen, W., Spahl, W. and Leyhausen, G. (1998) Residual monomer/additive release and variability in cytotoxicity of light-curing glass-ionomer cements and compomers. Journal of Dental Research, 77, 2012-2019. doi:10.1177/00220345980770121001

[7] Hanks, C.T., Strawn, S.E., Wataha, J.C. and Craig, R.G. (1991) Cytotoxic effects of resin components on cultured mammalian fibroblasts. Journal of Dental Research, 70, 1450-1455. doi:10.1177/00220345910700111201

[8] Issa, Y., Watts, D.C., Brunton, P.A., Waters, C.M. and Duxbury, A.J. (2004) Resin composite monomers alter MTT and LDH activity of human gingival fibroblasts in vitro. Dental Materials, 20, 12-20. doi:10.1016/S0109-5641(03)00053-8

[9] Wataha, J.C., Rueggeberg, F.A., Lapp, C.A., Lewis, J.B., Lockwood, P.E., Ergle, J.W. and Mettenburg, D.J. (1999) In vitro cytotoxicity of resin containing restorative materials after aging in artificial saliva. Clinical Oral Investigations, 3, 144-149. doi:10.1007/s007840050093

[10] Pulgar, R., Olea-Serrano, M.F., Novillo-Fertrell, A., Rivas, A., Pazos, P., Pedraza, V., Navajas, J.M. and Olea, N. (2000) Determination of bisphenol A and related aromatic compounds released from bis-GMA-based composites and sealants by high performance liquid chromatography. Environmental Health Perspectives, 108, 2127. doi: $10.2307 / 3454291$

[11] Kaga, M., Noda, M., Ferracane, J.L., Nakamura, W., Oguchi, H. and Sano, H. (2001) The in vitro cytotoxicity of eluates from dentin bonding resins and their effect on tyrosine phosphorylation of L929 cells. Dental Materials, 17, 333-339. doi:10.1016/S0109-5641(00)00091-9

[12] Geurtsen, W. (2000) Biocompatibility of resin-modified filling materials. Critical Reviews in Oral Biology and Medicine, 11, 333-355. doi:10.1177/10454411000110030401

[13] Craig, R.G. (1997) Restorative Dental Materials. $10^{\text {th }}$ Edition, Mosby-Year Book, Inc., St Louis.
[14] Moszner, N. and Salz, U. (2001) New developments of polymeric dental composites. Progress in Polymer Science, 26, 535-576. doi:10.1016/S0079-6700(01)00005-3

[15] Sulong, M.Z.A.M. and Aziz, R.A. (1990) Wear of materials used in dentistry: A review of the literature. The Journal of Prosthetic Dentistry, 63, 342-349.

[16] Quinlan, C.A., Zisterer, D.M., Tipton, K.F. and O'Sullivan, M.I. (2002) In vitro cytotoxicity of a composite resin and compomer. International Endodontic Journal, 35, 47-55.

[17] Mjor, I.A. (1990) Current views on biological testing of restorative materials. Journal of Oral Rehabilitation, 17, 503-507. doi:10.1111/j.1365-2842.1990.tb01421.x

[18] Thonemann, B., Schmalz, G., Hiller, K.A. and Schweikl, H. (2002) Responses of L929 mouse fibroblasts, primary and immortalized bovine dental papilla-derived cell lines to dental resin components. Dental Materials, 18, 318323. doi:10.1016/S0109-5641(01)00056-2

[19] Xie, D., Yang, Y., Zhao, J., Park, J.G. and Zhang, J.T. (2007) A novel comonomer-free light-cured glass-ionomer system for reduced cytotoxicity and enhanced mechanical strength. Dental Matererials, 23, 994-1003.

[20] Wataha, J.C., Rueggeberg, F.A., Lapp, C.A., Lewis, J.B., Lockwood, P.E., Ergle, J.W. and Mettenburg, D.J. (1999) In vitro cytotoxicity of resin-containing restorative materials after aging in artificial saliva. Clinical Oral Investigations, 3, 144-149. doi:10.1007/s007840050093

[21] Wisithphrom, K., Murray, P.E. and Windsor, L.J. (2006) Interleukin-1 alpha alters the expression of matrix metalloproteinases and collagen degradation by pulp fibroblasts. Journal of Endodontics, 32, 186-192.

[22] Zhou, J. and Windsor, L.J. (2006) Porphyromonas gingivalis affects host collagen degradation by affecting expression, activation, and inhibition of matrix metalloproteinases. Journal of Periodontal Research, 41, 47-54.

[23] Tominaga, H., Ishiyama, M., Ohseto, F., Sasamoto, K., Hamamoto, T., Suzuki, K. and Watanabe, M. (1999) A water-soluble tetrazolium salt useful for colorimetric cell viability assay. Analytical Communications, 36, 47-50. doi:10.1039/a809656b

[24] Lönnroth, E.C. and Dahl, J.E. (2003) Cytotoxicity of liquids and powders of chemically different dental materials evaluated using dimethylthiazol diphenyltetrazolium and neutral red tests. Acta Odontologica Scandinavica, 61, 52-56.

[25] Aranha, A.M., Giro, E.M., Souza, P.P., Hebling, J. and de Souza Costa, C.A. (2006) Effect of curing regime on the cytotoxicity of resin-modified glass-ionomer lining cements applied to an odontoblast-cell line. Dental Materials, 22, 864-869. doi:10.1016/j.dental.2005.11.015

[26] Stanislawski, L., Daniau, X., Lauti, A. and Goldberg, M. (1999) Factors responsible for pulp cell cytotoxicity induced by resin-modified glass ionomer cements. Journal of Biomedical Materials Research, 48, 277-288.

[27] Beriat, N.C., Ertan, A.A., Canay, S., Gurpinar, A. and Onur, M.A. (2010) Effect of different polymerization methods on the cytotoxicity of dental composites. European Journal of Dentistry, 4, 287-292.

[28] Kleverlaan, C.J. and Feilzer, A.J. (2005) Polymerization shrinkage and contraction stress of dental resin composites. Dental Materials, 21, 1150-1157. doi:10.1016/j.dental.2005.02.004

[29] Momoi, Y., Hirosaki, K., Kohno, A. and McCabe, J.F. 
(1995) Flexural properties of resin-modified "hybrid" glass-ionomers in comparison with conventional acid-base glass-ionomers. Dental Materials Journal, 14, 109-119.

[30] Schmid-Schwap, M., Franz, A., Konig, F., Bristela, M., Lucas, T., Piehslinger, E., Watts, D.C. and Schedle, A. (2009) Cytotoxicity of four categories of dental cements. Dental Materials, 25, 360-368.

[31] Xie, D., Faddah, M. and Park, J.G. (2005) Novel amino acid modified zinc polycarboxylates for improved dental cements. Dental Materials, 21, 739-748. doi:10.1016/j.dental.2005.01.008

[32] Wilson, A.D. and McLean, J.W. (1988) Glass-ionomer cements. Quintessence Publ Co., Chicago.

[33] Nicholson, J.W., Braybrook, J.H. and Wasson, E.A.
(1991) The biocompatibility of glass-poly(alkenoate) (Glass-Ionomer) cements: A review. Journal of Biomaterials Science, 2, 277-285. doi:10.1163/156856291X00179

[34] Wasson, E.A. and Nicholson, J.W. (1993) Change in pH during setting of polyelectrolyte dental cements. Journal of Dentistry. 21, 122-126.

[35] Borovansky, J. and Riley, P.A. (1989) Cytotoxicity of zinc in vitro. Chemico-Biological Interactions, 69, 279291. doi:10.1016/0009-2797(89)90085-9

[36] Stanislawski, L., Daniau, X., Lauti, A. and Goldberg, M. (1999) Factors responsible for pulp cell cytotoxicity induced by resin-modified glass ionomer cements. Journal of Biomedical Materials Research, 48, 277-288. 